\title{
Héroes de papel: El deporte y la prensa como herramientas de propaganda política del fascismo y el franquismo. Una perspectiva histórica comparada.
}

\author{
Alejandro ViUdA-SERRANO \\ Universidad Camilo José Cela \\ adelaviuda@gmail.com \\ Teresa GonZÁLEZ AJA \\ Universidad Politécnica de Madrid \\ tglezaja@gmail.com
}

Recibido: 12 de julio de 2012.

Aceptado: 24 de agosto de 2012.

\section{Resumen}

Esta investigación se plantea definir los mecanismos de apropiación y utilización del deporte y la prensa como elementos de legitimación y propaganda, que los regímenes fascista y franquista llevaron a cabo en el periodo de entreguerras. Se establecerá una comparación, desde el punto de vista histórico, entre Benito Mussolini y Francisco Franco, así como entre sus respectivas ideologías y modos de actuación. Para ello se utilizarán fuentes de archivo y publicaciones periódicas de la época, tanto de Italia como de España, así como las investigaciones más importantes de otros autores que han trabajado sobre temas de interés para este estudio. El objetivo es realizar una aportación historiográfica relevante y novedosa.

Palabras clave: Deporte; prensa; Mussolini; Franco; propaganda; adoctrinamiento ideológico.

\section{Paper heroes: Sport and press as fascism and francoism political propa- ganda issue. A comparative historical view}

\begin{abstract}
This manuscript seeks to define the mechanisms of appropriation and use of Sport and Press as legitimation and propaganda means carried out along the interwar years by fascist and francoist regimes. A historical comparison between Benito Mussolini and Francisco Franco and also between their ideologies and behaviors was needed. In order to do so archive documents and periodicals of that period, in Italy and Spain, as well as the most important scholar researches on the topic have been analyzed. The aim is to get a relevant and innovative historiographical contribution.
\end{abstract}

Key words: Sport; Press; Mussolini; Franco; propaganda; ideological indoctrination.

\section{Referencia normalizada}

Viuda-Serrano, A.; González Aja, T. (2012). Héroes de papel: El deporte y la prensa como herramientas de propaganda política del fascismo y el franquismo. Una perspectiva histórica comparada. Historia y Comunicación Social, Vol. 17, páginas 41-68. 
Sumario: 1. Introducción. 2. La relación Mussolini-Franco 3. La utilización del deporte por el fascismo y el franquismo. 3.1. Mussolini y el Deporte. 3.2. Franco y el deporte. 4. La utilización de la información por el fascismo y el franquismo. 4.1. Mussolini y la prensa. 4.2. Franco y la prensa. 5. Conclusiones. 6. Bibliografía.

\section{Introducción}

Con toda seguridad, las dictaduras son mucho más difíciles de estudiar que las democracias dado que sus políticas internas se esconden de manera deliberada a la luz pública (Lewis, 2002, p. 1), lo cual no implica en absoluto que no se recurra a métodos de ocultación en las democracias. Dado que el objetivo de este artículo no es la teorización terminológica, utilizamos ambos términos -dictadura y democraciaen un sentido amplio, entendiendo que las dictaduras de toda clase y orientación presentan ciertas necesidades "de partida" que las democracias no tienen, y que derivan de los problemas de legitimidad inherentes a ellas; legitimidad de origen y legitimidad de ejercicio, en el sentido que inicia Rousseau en su Contrato social (2007 [1762]) y que estudia Ferrero en El poder (1991 [1942]), dado que los dictadores suelen afanarse por obtener esa legitimidad, sustituyendo los iniciales mecanismos de fuerza por otros de control más tolerables para los gobernados.

Utilizamos también el término fascismo en sentido amplio, para describir toda una serie de movimientos políticos que tuvieron su origen en la Europa de entreguerras durante la primera mitad del siglo XX, algunos de los cuales sobrevivieron hasta casi el último tercio del siglo. Sin embargo, también lo usaremos en sentido restringido para referirnos en concreto al sistema político italiano durante los años de gobierno de Benito Mussolini. Aunque el término no surgiera del estudio histórico analítico sino de la propia política, para algunos autores resulta suficientemente intuitivo y genérico como para considerarlo el mejor disponible (Turner Jr., 1975, p. 133), así como para poder adscribir bajo él a regímenes con diferencias pero también con claras similitudes. A efectos teóricos, muchos estudiosos han usado el término fascismo como opuesto a comunismo y han querido ver en ambos las dos caras de un mismo fenómeno (Arendt, 1960; Friedrich \& Brzezinski, 1965). Algunos han generalizado tanto el concepto que cualquier régimen autoritario, radical y nacionalista podría ser considerado fascista (Gregor, 1974), lo que, a nuestro juicio, hace que el término se vacíe de significado. Otros, sin embargo, lo han constreñido hasta circunscribirlo a uno o dos regímenes a lo sumo (De Felice, 1976). Woolf (1965) entiende que fascismo define a toda una serie de regímenes diferentes pero con las mismas bases, así como democracia define a otros tantos sistemas políticos muy distintos entre sí pero con rasgos básicos comunes. Payne (2009 [1982], pp. 21-28) afirma que existieron movimientos fascistas en toda Europa, entre los que incluye la Falange española, que hay que distinguir de las otras dos caras del nacionalismo autoritario: la derecha radical y la derecha conservadora. Lewis (2002) denomina como fascistas los regímenes de Hitler (1933-1945), Mussolini (1922-1945), Franco (1939-1975) u Oliveira Salazar (1932-1968) lo que, si bien puede parecerles a algunos estudiosos poco escrupuloso en términos históricos, resulta significativa- 
mente clarificador para el lector a efectos clasificatorios y/o comparativos. Passmore (2002, pp. 11-12) cree que tal diversidad de movimientos y regímenes considerados bajo una misma denominación puede ocultar las claras y básicas diferencias entre ellos. Al fin, habrá que asumir con Ortega y Gasset (2007, p. 106) que el fascismo

“tiene un cariz enigmático, porque aparecen en él los contenidos más opuestos. Afirma el autoritarismo, y a la vez organiza la rebelión. Combate la democracia contemporánea y, por otra parte, no cree en la restauración de nada pretérito. Parece proponerse la forja de un Estado fuerte y emplea los medios más disolventes [...]. Por cualquier parte que tomemos el fascismo, hallamos que es una cosa y a la vez la contraria".

Nosotros, en los términos en que planteamos esta investigación, y teniendo en cuenta el análisis que hace De Felice (1976, p. 72), que afirma que el régimen español no fue fascista, nos centraremos en Franco y Mussolini, en cuanto líderes del franquismo y el fascismo respectivamente, pero destacaremos un buen número de rasgos en común ${ }^{1}$, dado que durante los primeros años del régimen de Franco existió un importante componente de tipo fascista, e incluso una clara identificación (Preston, 1986, p. 18 y ss.), lo cual explica por qué se dio un intento evidente de imitación de los modos, la ideología, los mitos y la organización de la Italia de Mussolini.

La falta de transparencia, apuntada al inicio de esta introducción, que caracteriza a las dictaduras tiene su clara concreción en la censura férrea que todas ellas ejercen sobre la vida social, política y cultural para conseguir la legitimidad que no poseen. La educación será el medio principal de adoctrinamiento desde el Estado para lograr la aceptación y la asunción del nuevo ideario por parte de la sociedad. A su vez, las dos herramientas educativas más potentes que posee un Estado, además de la propia educación reglada en las escuelas, son el deporte y los medios de comunicación (Viuda-Serrano, 2010b, p. 158). Por tanto, parece lógico que sean estos los dos ejes básicos en torno a los cuales gravite nuestro estudio.

Como fuente básica de la investigación se ha utilizado documentación recopilada en el Archivio Centrale dello Stato de Roma y el Archivo General de la Administración de Alcalá de Henares, además de material hemerográfico de procedencia diversa correspondiente a publicaciones periódicas entre los años 1920 y 1945, con el objetivo de obtener evidencias historiográficamente relevantes sobre el tema de estudio.

\section{La relación Mussolini-Franco}

Tal y como afirman Tusell y García Queipo de Llano (2006, p. 9) “difícilmente pueden ser imaginadas dos personalidades más antitéticas que las de los dos dictadores más duraderos e históricamente relevantes del Mediterráneo en el siglo XX: Franco y Mussolini". A pesar de este hecho, los avances de la historiografía actual no dejan lugar a dudas a la hora de afirmar que la relación de ambos fue no solo 
personal sino también ideológica sobre la base de diversos intereses comunes o, cuando menos, complementarios ${ }^{2}$. Es cierto que las relaciones de Mussolini con España se remontan a los años 20. Esta cuestión ha sido tratada en otros estudios ${ }^{3} \mathrm{y}$ no es objeto de la presente investigación. Baste decir que Mussolini accede al poder en 1922, solo unos meses antes de que haga lo propio Miguel Primo de Rivera en España, y que entre ambos dictadores se establece un vínculo, no demasiado profundo, materializado en sucesivos acuerdos comerciales (1923 y 1928) y basado en la admiración del militar español por el Duce y en el intento de utilización mutuo: de la posición internacional española por parte de Mussolini, y del apoyo italiano en sus pretensiones coloniales en el norte de África por parte de Primo de Rivera.

La oposición de Mussolini a la República española fue clara y, si bien intentó mantener una relación diplomática cordial, apoyó los distintos movimientos subversivos conservadores que fueron formándose entre 1932 y 1936 (Tusell \& García Queipo de Llano, 2006, pp. 16-19). Al mismo tiempo, Italia trató de sacar beneficio de la difícil situación política de España en los meses anteriores a la guerra civil, y el embajador italiano en Madrid solicitó un fondo extraordinario de 30.000 pesetas, concedido cuatro días más tarde, viendo "la posibilidad de influir eficazmente, por medio de la prensa, en la opinión pública" ("Appunto per S. E. il Ministro per la Stampa e la Propaganda," 1936, 20 Gennaio). No se puede sostener, sin embargo, que Italia tuviera un papel activo en la sublevación del 18 de julio, fecha en la que su confianza en las posibilidades de la derecha española para derribar a la República eran escasas. No será hasta unos días después, cuando Mussolini envíe aviones y carros de combate a Franco. Esta intervención italiana, tímida al principio, se explica fundamentalmente en base a la creencia del Duce de que a bajo coste podía conseguir en España un aliado en el Mediterráneo para sus intereses imperialistas. Decimos a bajo coste puesto que la ayuda italiana descansaba en la expectativa de una rápida victoria de Franco y sus generales; rapidez que no fue tal, a pesar de lo cual la intervención italiana se mantuvo ${ }^{4}$. Esta fue con mucho la más importante y decisiva aportación de cuantas recibieron los sublevados: "Cerca de 80.000 italianos [...]; 759 aviones, alrededor de 6.600 cañones, morteros y ametralladoras, 157 tanques, cientos de miles de fusiles y millones de proyectiles y cartuchos" (Saz Campos, 1992, p. 124). Así lo aseguraba también el propio régimen fascista que calificaba su ayuda militar a Franco de "esfuerzo colosal de Italia por la independencia de la España nacional" encuadrando la intervención dentro de "la acción global de guerra de Italia" ("Disposizione dal Ministero della Cultura Popolare," 1941, 27 febbraio). Con seguridad la ayuda de Italia (y, por supuesto, de Alemania) a Franco fue factor decisivo de su victoria en la guerra civil y sin ella las cosas hubieran seguido un camino bien distinto (Southworth, 2008 [1964], p. 88; Thomas, 1976, p. 1006).

En su idea de llevar el fascismo a toda Europa (Murro, 1931, p. 6), Mussolini intentaría influir durante y después de la guerra para establecer en España un Estado de estilo fascista. No en vano él mismo afirmaría ya en 1931 que "tras un decenio Europa será fascista o fascistizada" (Mussolini, 1931a, p. 3). No viendo en España un potencial competidor por la supremacía en el Mediterráneo trató de atraerla hacia 
su órbita de influencia. Y, sin duda, lo logró. El decreto de unificación ("Decreto 255 de 19 de abril," 1937) para la creación de un partido único, a pesar de que con toda probabilidad ya estaba en los planes de Franco, fue alentado por Italia en el mismo mes de febrero de 1937 mediante la "misión Farinacci", llamada así por Roberto Farinacci, emisario personal de Mussolini, enviado a España con el objetivo de "recomendar la creación de un Partido nacional, único, fuerte, autoritario y totalitario encabezado por Franco" (Saz Campos, 1992, p. 115). La estética de elementos fascistizados quedaba evidenciada por la instauración del saludo fascista como saludo nacional ("Decreto 263 de 24 de abril," 1937). El Fuero del Trabajo ("Decreto de 9 de marzo," 1938) tuvo grandes influencias de la Carta del Lavoro italiana (1927). La Ley de Prensa (1938) que establecía los mecanismos de censura estuvo sin duda inspirada en las leyes sulla stampa de los años 20 en la Italia fascista. En febrero de 1939, antes incluso de acabada la guerra civil, España se adhiere al pacto Antikomintern, si bien acordando mantenerlo en secreto. La victoria de Franco es vista como el aplastamiento del comunismo en Europa y su aislamiento en Rusia. La estructuración organizativa del deporte tras la guerra civil también estuvo muy influenciada, del mismo modo que lo estuvo el deporte nazi, por el modelo de deporte estatal de Mussolini. En fin, la intervención italiana en la guerra de España había supuesto un éxito rotundo dada la clara orientación italianófila que el nuevo Estado iba tomando, y que se completó con la emergencia de la figura de mayor altura política de España en los dos últimos años de la guerra y los tres primeros de la posguerra: Ramón Serrano Suñer, gran conocedor y admirador de la Italia fascista y político muy del gusto de Mussolini. Franco pretendería después que su régimen no bebió de ninguna fuente que no fueran las tradiciones españolas. Diría en junio de 1958, en declaraciones al diario francés Le Figaro (Franco Bahamonde, 1975a, pp. 434-435; Groussard, 1958), que Mussolini moldeó

una ideología original y poderosa. Pero para nosotros, los españoles, ninguna ética extranjera hubiese podido convenir. Durante la República nuestro país ha querido imitar a algunos Regímenes extranjeros. El resultado fue un duro período de caos. [...] Nuestro Régimen actual tiene exclusivamente sus fuentes y su fundamento en la Historia española, en nuestras tradiciones, nuestras instituciones, nuestra alma.

Sin embargo, no cabe duda de la gran influencia italiana, a pesar del carácter diferenciador que supuso la moral católica en el caso español y que llevó a acuñar el término "nacionalcatolicismo".

Por otro lado, en esta ligazón de los caminos de Franco y Mussolini, y en el propio éxito de la intervención italiana en España, radicaría el fracaso de la política exterior fascista en los años posteriores, por la hipotecada relación de amistad con Inglaterra y la rápida y subordinada aproximación a Alemania. Ambas razones llevarían a la Italia de Mussolini al desastre ante la sustitución de la prevención anticomunista, imperante hasta la guerra española, por la prevención frente a la nueva amenaza del fascismo creciente 5 . Mientras, la España de Franco fue salvando obstáculos para evitar ser engullida por los acontecimientos internacionales. Gran parte de la historiografía actual coincide al señalar que la "neutralidad" o la "no beli- 
gerancia" de Franco frente a la segunda guerra mundial fue más fruto de la imposibilidad material de entrar en el conflicto y de la negativa de Alemania ante lo que consideraba más un coste que un beneficio, que de la planificada política de Franco, por mucho que a posteriori tanto este como Serrano Suñer afirmaran la existencia de dicha planificación. Franco diría justamente tras la rendición de Alemania en el pleno del Consejo Nacional del Movimiento celebrado en Madrid el 17 de julio de 1945 (Franco Bahamonde, 1975b, p. 767):

Rondó la guerra nuestras aguas y nuestros territorios, se acercó a nuestras fronteras, y, sin embargo, España se mantuvo firme y en paz; y hasta en aquellos momentos en que en el mundo se juzgaba la guerra decidida y en que los más avisados consideraban las ventajas materiales que podían obtener con la intervención, nuestra nación mantuvo su neutralidad y evitó la guerra sobre sus territorios.

Serrano Suñer se esforzó también (Serrano Suñer, 1977) por mostrar que la no entrada de España en la segunda guerra mundial fue el éxito de un plan premeditado y llevado a cabo con gran astucia por Franco y él mismo. Sin embargo, el propio Serrano admitiría años más tarde (Saña, 1981, p. 170) que en 1940

Teníamos el convencimiento de que la guerra estaba terminada, de que no había que perder días. Pensábamos que si España participaba en la guerra aunque fuese simplemente una semana, sus derechos y su crédito en la Conferencia de la Paz serían muy distintos a que si simplemente se limitaba a aplaudir, que es lo que hacíamos.

Cuando las potencias del Eje fueron derrotadas, la amenaza comunista volvió a emerger con fuerza, lo que dio a Franco la oportunidad de aparecer más como país anticomunista y católico que como aliado del fascismo europeo. Así, en unos años terminaría entrando en las instituciones políticas mundiales y normalizando sus relaciones internacionales. Finalmente, el factor ideológico, aquel que había unido a los dos dictadores mediterráneos, terminó por hundir a Mussolini y salvar a Franco.

\section{La utilización del deporte por el fascismo y el franquismo}

La relación entre deporte y política ha sido siempre controvertida dado que los gobiernos han tratado de adaptar el deporte a sus propósitos particulares (González Aja, 2010, p. 196). A su vez, el uso político del deporte como tema de investigación histórica ha arrojado multitud de contribuciones en las últimas décadas ${ }^{6}$, dado el interés que suscita. Mayor interés, si cabe, ha despertado la utilización del deporte por los regímenes totalitarios y, en especial, por aquellos que podemos colocar en la órbita del fascismo europeo de la primera mitad del siglo XX: el nazismo alemán, el fascismo italiano y el franquismo español ${ }^{7}$. Si bien cada uno de ellos tiene características diferenciadoras y específicas, no podemos obviar rasgos básicos en común. De entre ellos, el más importante en este punto de nuestra investigación es la subordinación de los deportistas individuales al Estado (Guttmann, 2004, p. 293). En todo 
caso, el deporte desarrollado en estos regímenes es claramente distinto del que se llevó a cabo en los países democráticos de la época. Sin embargo, lo novedoso no es el uso del deporte para crear una idoneidad física nacional y lograr al mismo tiempo la demostración palpable de su superioridad a través de las hazañas deportivas; lo realmente nuevo es el uso a gran escala del deporte como medio de adoctrinamiento (Krüger, 1999, p. 67), en este caso para implantar sistemas totalitarios con clara vocación de permanencia en el tiempo.

\subsection{Mussolini y el deporte}

El caso italiano, es probablemente el más interesante, puesto que será el modelo tanto para la Alemania nazi como para la España franquista. A pesar de que con Hitler el uso del deporte alcanzaría mayor extensión y eficacia, y con Franco mayor longevidad, será Benito Mussolini quien reviva la noción clásica olvidada del deporte como herramienta política. Sin duda, este destaca sobre las figuras de sus homólogos alemán y español por su físico atlético y su gusto por el deporte 8 . Practicaba asiduamente la esgrima, la equitación, el esquí o la natación. Él mismo diría, "sin ninguna añoranza, he abandonado todo bienestar útil de la vida. Mi único placer es el deporte" (Mussolini, 1928). Representó "el modelo de Superman" con el que los italianos debían identificarse (Gori, 2000, p. 27). La ideología fascista fue una especie de "religión cívica" en la que se exigía la fe en el Duce como líder y modelo. Se buscaba la aceptación popular. Es la llamada "política del consenso" que han definido diversos autores (De Felice, 1974; Gori, 2000; Krüger, 1999) o "cultura del consenso", definida por primera vez por De Grazia (1981). Y es que, como concluye el propio De Felice (1976, pp. 49, 90), el fascismo, tanto en su emergencia como en su afirmación, es un fenómeno que surge de las clases medias, en un intento por constituirse en una nueva fuerza, usando soluciones "modernas".

Explotando los errores socialistas y católicos para lograr la movilización de la sociedad italiana, el fascismo se presentó como la única solución posible ante la grave crisis de la posguerra mundial, para lograr paz, orden y progreso. Mussolini tomó el control del deporte y lo orientó hacia la regeneración social. Se trataba de educar a la juventud, de crear el "italiano nuevo, es decir, fuerte de espíritu, robusto en los músculos y sano, en la más amplia expresión ética de la palabra" (Varale, 1930 , p. 2). Los valores del país se repensaron para convertir el deporte en la manifestación cultural más importante de Italia. Entre los atributos que le confiere el propio Mussolini a ese nuevo hombre ${ }^{9}$ que pretende forjar figuran:

la tenacidad en el trabajo; la extrema parsimonia del gesto y la palabra; el coraje físico y moral; la lealtad absoluta en las relaciones de la vida; la firmeza en la decisión; el afecto por sus camaradas; el odio por los enemigos de la Revolución y de la Patria; la fidelidad sin límites al juramento dado; el respeto de la tradición y al mismo tiempo el ansia del mañana (Mussolini, 1931b, p. 3).

La mistificación de la figura del líder como ese hombre nuevo, ejemplo a seguir por todo el pueblo italiano, requería de un planificado proceso de glorificación 
personal. A ello se dedicó la maquinaria del régimen. Se construyó el mito del "duce deportista" en dos ámbitos: la actividad físico-deportiva llevada a cabo en primera persona por el propio Mussolini; y su presencia constante en los eventos deportivos importantes (Impiglia, 2009, p. 21). En Gioventù Fascista, publicación del Partito Nazionale Fascista dirigida por Achille Starace, la mayoría de las portadas tienen a Mussolini como protagonista, en varias ocasiones realizando o viendo actividad deportiva ${ }^{10}$. En las páginas iniciales del primer número de la revista Lo Sport Fascista, Lando Ferretti, director de la publicación, describía a Mussolini como "el Duce aviador, esgrimista, jinete; el Duce primer deportista de Italia" (Ferretti, 1928b, p. 4). Serán muchas las fotografías de Mussolini en actitud deportiva que aparezcan en las publicaciones de la época ${ }^{11}$. También los textos de exaltación; y sin duda el más rendido panegírico deportivo dirigido al Duce será el que le dedique el propio Ferretti en el número de Lo Sport Fascista de enero de 1933. En él, lo exalta de manera sublime preguntándose "qué ocultos e inagotables tesoros de potencia posee" para parecer "cada vez más ágil y fuerte". Describe sus prácticas deportivas. En fin, le caracteriza como "generosa personificación del triunfante deporte de Italia". Lo hace todo y lo hace bien (Ferretti, 1933, pp. 1-3). Como puede verse, "el mito del Mussolini deportista es una mezcla de ficción, realidad, narcisismo, capacidad, pasión y fría especulación. La figura de un César gladiador que en retrospectiva parece grotesca, pero que a muchos se les reveló sólida y verdadera como el granito de Roma" (Impiglia, 2009, p. 45). Lo que se consiguió con todo ello fue una identificación total entre el fascismo y Mussolini, una suerte de "Mussolinismo" (Gori, 2000, p. 38).

El régimen fascista invirtió recursos ingentes en educación física y salud a través de la organización por parte del partido del tiempo de ocio de las personas y del deporte competitivo, además de la construcción de instalaciones. El objetivo no era otro que lograr cuerpos ejercitados y mentes ocupadas para lograr un glorioso futuro. A cambio de esta inversión, el fascismo reclamaba la lealtad a sus principios. El resultado fue la politización del deporte italiano a todos los niveles (Martin, 2004, p. 15). En vez de acabar con la organización deportiva anterior, el régimen eligió la opción, mucho más pragmática, de reestructurar los organismos precedentes en un sentido claramente paramilitar imponiendo su propio espíritu y disciplina fascistas y desarrollando su trasfondo político (Guttmann, 2004, p. 293; Martin, 2004, p. 32). Así se fundaron sólidas bases para llevar a cabo la labor deportiva creando entre 1925 y 1926 las dos instituciones básicas para el adoctrinamiento a través del deporte: La Opera Nazionale Balilla $(\mathrm{ONB})^{12}$, organización para los niños y adolescentes, sustituida en 1937 por la Gioventù Italiana del Littorio (GIL) ${ }^{13}$, y la Opera Nazionale de Dopolavoro (OND) ${ }^{14}$, organización para los trabajadores. La ONB ofrecía educación física extraescolar para niños y niñas de 8 a 18 años, divididos en balilla (de 8 a 14) y avanguardisti (14-18); la OND, organizaba actividades recreativas y deportes para el tiempo de ocio de los trabajadores. Además, otras dos organizaciones, fundadas antes de la subida al poder de Mussolini, terminan de cerrar el círculo de influencia deportiva: los Gruppi Universitari Fascisti (GUF) ${ }^{15}$ y el propio Comitato Olimpico Nazionale Italiano (CONI) ${ }^{16}$. Los GUF controlaban la 
actividad física (además de otro tipo de actividades) de los universitarios en todas las regiones del país; el CONI la actividad deportiva de competición. Efectivamente, todos los ámbitos de la sociedad quedaban así controlados a través del deporte, máxime cuando la pertenencia a la ONB era requisito previo para poder inscribirse en un club deportivo o para competir con el CONI, y la pertenencia a la GIL (a partir de 1937) era obligatoria para los rangos de edad antedichos. Además, ya en 1927 el régimen había disuelto las organizaciones deportivas asociadas con la Iglesia Católica, la YMCA y los Boy Scouts, no existiendo, por tanto, competencia alguna (Guttmann, 2004, p. 294; Teja, 2002, p. 252).

Hubo, sin embargo, como afirma Teja (2002, pp. 241-243), etapas diferenciadas en la política deportiva fascista en Italia. Durante los años 20, el régimen seguía una orientación claramente pedagógica e higiénica privilegiando la educación física y menospreciando la competición, centrándose en la actividad grupal y desechando los logros individuales: "El fascismo ha creído siempre que (el deporte) debe considerarse primero una cuestión de masa y después de individualidad" (Parboni, 1928, p. 4). El objetivo no era otro que moldear el cuerpo y el carácter de los jóvenes de acuerdo a los ideales fascistas (Vescovi, 2003, p. 166). Renato Ricci será quien durante más de una década dirija la educación física de la juventud y luche por imponer su criterio de excluir el deporte de la escuela y someterlo al partido: "El fascismo ha fusionado el principio deportivo con el militar [...] y ha puesto normas para la preparación de los adolescentes y los jóvenes" (Parboni, 1928, p. 3).

En los años 30, en cambio, el régimen empezó a ver las ventajas de la competición al tiempo que se demostraban los beneficios propagandísticos de los logros deportivos a nivel internacional. La figura de Lando Ferretti, presidente del CONI, emerge como ideólogo de esta nueva etapa, con el añadido de que entre 1928 y 1931 fue también responsable del control de toda la prensa nacional. Se buscan de manera nítida los campeones y las masas deportivas de espectadores, olvidada ya la importancia de la actividad física educativa de años atrás. El deporte pasa a ser un importante elemento de política exterior, un plano más de la lucha diplomática. Tal y como afirma Ferretti en Lo Sport Fascista (1928a, p. 4), “[...] tenemos el coraje de proclamar que el deporte es para nosotros instrumento de propaganda y de fuerza de la Nación en cualquier tiempo y en cualquier circunstancia”.

La retórica militarista comienza a extenderse también a la prensa: "Mussolini hace bien en tener a los jóvenes, es decir, a Italia, a alta temperatura porque sabe que en el mundo no hay tregua ni piedad para los que se dejan sorprender" (Varale, 1933, p. 4). En 1934 el CONI se hace con el poder total del deporte italiano a todos los niveles. Con el nacimiento de la GIL el deporte se unirá pronto a otra importante figura, Achille Starace, también presidente del CONI. La fascistización del deporte era ya completa, pasando el propio deporte a un segundo plano, como mero instrumento de propaganda. Este segundo plano, se verá aún más claro durante los años de la guerra mundial en que las fotografias de deportistas son puestas al servicio de la propaganda bélica, y son muy habituales las imágenes de hombres en pantalón corto, símbolo de "virilidad" ("Rapporto ai giornalisti del 14 settembre," 1940).

Existieron, por supuesto, movimientos en contra de esa utilización del deporte. 
Uno de los más interesantes fue Giustizia e Libertà, movimiento liberal-socialista y antifascista creado en 1929. Para el notable escritor Carlo Levi (que escribía bajo el pseudónimo de E. Bianchi), a mitad de los años 30 el deporte había derivado en la única ocupación de los italianos y el fascismo lo había convertido en un instrumento de propaganda y control social. "Porque amamos el deporte no lo queremos instrumento servil [...]. Deporte y fascismo son términos antitéticos" (Bianchi, 1934).

Sin embargo, los grandes éxitos a nivel internacional que el deporte fascista cosechó terminaron por hacer realidad el éxito rotundo del sistema impuesto por Mussolini. Italia fue campeona del mundo de fútbol en el Mundial de 1934 que ella misma organizó, y en el de 1938, disputado en Francia; en los Juegos Olímpicos de Los Ángeles 1932, el equipo italiano fue segundo en número de medallas, y en los de Berlín 1936, tercero; además, ganó los Juegos Universitarios Internacionales de 1933, en Turín y quedó segunda, tras Alemania, en los de 1939, en Viena ${ }^{17}$.

En definitiva, y como afirma Teja (2002, p. 241), "durante el período fascista la actividad deportiva se inscribió dentro de una acción programada por el Estado para controlar [...], de un modo casi total, al ciudadano, ya fuese en su dimensión privada, en sus relaciones interpersonales o en su vida social".

\subsection{Franco y el deporte}

El objetivo básico planteado en todos los ámbitos y actividades de España -la supervivencia del régimen político de Franco- va a mediatizar los más de 39 años de dictadura. $\mathrm{Y}$ es que el franquismo no posee una estética concreta, porque tampoco tiene una doctrina clara. Es más bien la amalgama de una cambiante correlación de fuerzas entre falangistas, tradicionalistas, monárquicos y católicos y, sobre todo, es la trayectoria vital de un hombre, el general Franco, a través de distintos momentos con el único objetivo de sobrevivir (González Aja, 2000, p. 131).

La política deportiva durante el franquismo presenta una enorme complejidad, debido a la gran cantidad de cambios políticos y sociales que se produjeron y que afectaron a todos los niveles de la vida de los españoles; también al deporte. Sin embargo, al contrario que Mussolini, Franco no era un deportista en ningún sentido. En contraposición con el carácter revolucionario de aquel, este encarna la mentalidad conservadora del viejo estilo militar, y el deporte no le atrae en exceso. Como afirma Krüger (1999, p. 81), su fuerza se consideraba más moral que física y su gusto por los valores tradicionales españoles le llevó a ser espectador asiduo de los toros o el fútbol. No obstante, practicó algunos deportes para los que las excelencias físicas no eran primordiales, como la pesca, el golf o, sobre todo, la caza. La cultura del consenso, definida para el caso italiano, se transforma en "cultura de la evasión" en la España de este período (Carr \& Fusi Aizpurúa, 1979, p. 153). La imagen de Franco, si bien igual de mistificada que la de Mussolini, no suele aparecer casi nunca en actitudes deportivas sino siempre en funciones militares o políticas. En este sentido, hablar aquí del culto al cuerpo, significa hablar de la adaptación de modelos foráneos (básicamente Mussolini y Hitler) a las características específicas de Franco. Por tanto, y en ausencia de altas cualidades físicas que destacar, se defiende su 
apariencia por otras virtudes. Seguramente el mejor ejemplo de ello sea el elogio que Giménez Caballero hace en 1938 de "la sonrisa" del Caudillo (Cirici, 1977, pp. 7778). Afirma la originalidad del movimiento español y opone esa sonrisa a "la mirada" y "la forma de emproar la mandíbula" de Mussolini, o a los "recortados bigotes y tupé oblicuo" de Hitler. Ambos representan a sus pueblos: el italiano, deseoso de ser dirigido por su líder, y el alemán, disciplinado y en orden. Sin embargo, el pueblo español es "rebelde, rijoso, enconado, cabileño [...] rencoroso y envidioso". El Caudillo "tiene algo de manto de la Virgen tendido sobre los pecadores. Tiene ternura paternal y maternal a la vez"; es quien puede dar la paz al pueblo español, "sosegarlo, apaciguarlo, cicatrizarle las heridas". Aquí vemos ya las líneas básicas de la mistificación de Franco, no física sino moral: el poder de Franco emana de dios, con el respaldo de la Iglesia Católica ("Caudillo de España por la Gracia de Dios"); España es como un niño al que él cuida, diciéndole qué hacer en cada momento; ha traído la paz y la estabilidad a un país enfrentado y deshecho. Este es el origen de la legitimidad del régimen de Franco lograda mediante la propaganda de su imagen. No obstante, en España, al igual que en Italia, se defenderá el mito del hombre perfecto, que incluye lo corporal, aunque siempre prevalecerá la imagen del caballero perfecto, del "monje-soldado", austero y sacrificado (González Aja, 2000, p. 138).

Acevedo (1969, pp. 190-191) definió tres fases en el franquismo, coincidentes con tres generaciones distintas de españoles: la "generación politizada" (1936-46), la "generación futbolizada" (1947-66) y la "generación contestataria" (a partir de 1967). Esos casi 20 años de pasión por el fútbol por encima de cualquier otra cosa, ponen de manifiesto la importancia del deporte en la España franquista como cultura de la evasión, gracias a una despolitización claramente facilitada por la represión de los primeros años de dictadura. La articulación deportiva siguió sin duda el ejemplo italiano, como en la mayor parte de los ámbitos. Se crearon organizaciones deportivas similares a las italianas, poniendo de manifiesto la falta de un modelo deportivo propio. No obstante, lo más importante y novedoso será que "por vez primera el deporte dejaba de ser una actividad de organización formalmente privada con conexiones intermitentes y puntuales con los poderes públicos [...] para pasar a ser una actividad que se organizaría de forma jerárquica desde el poder político" (Santacana i Torres, 2011, p. 210).

Así, tenemos la creación del Frente de Juventudes (FJ) ${ }^{18}$, para Manrique (2011, p. 235) copia de las Hitler Jugend, pero para nosotros con muchas similitudes también con la ONB fascista, como principal organismo en política de juventud durante la primera mitad del régimen franquista. A esta institución pertenecían tanto el Sindicato Español Universitario (SEU) ${ }^{19}$ como la Sección Femenina (SF) ${ }^{20}$. El SEU se encargaría del deporte universitario, en línea con los GUF italianos, y la SF, que se separaría del FJ en 1945, se encargaría de la educación física de la mujer. Estas mujeres tendrán un papel fundamental en la Obra Sindical Educación y Descanso (OSED) ${ }^{21}$, similar a la OND de Mussolini. Incluso se crearon organismos durante la guerra civil llamados "después del trabajo", claro mimetismo del Dopolavoro italiano. Del FJ diría Franco (1975a, p. 327) que fue 
el instrumento más perfecto para enraizar el Movimiento [...]. Había que educar nuestros futuros hombres en un sentimiento común de servicio y sacrificio por la grandeza de la Patria, había que coger la cera virgen de nuestra juventud para moldear con ella los hombres nuevos.

Por último, la Delegación Nacional de Deportes (DND)22, que incluía en su seno al Comité Olímpico Español $(\mathrm{COE})^{23}$, tendrá similares atribuciones que el CONI en Italia.

Al igual que en el caso italiano, podemos hablar en España, siguiendo a Santacana (2011, p. 211 y ss.), de un primer período, hasta la muerte de Moscardó en 1956, en el que se intentó potenciar más la educación física que el deporte de competición o federado. Con seguridad, la razón básica era que en la educación de los más jóvenes es donde realmente se inculcan los nuevos valores. Así sucedió al menos en la teoría, en la legislación y en lo político; porque la realidad deportiva del país iba a encumbrar desde muy temprano el fútbol y el deporte espectáculo. No cabía otra cosa con la dura y larga miseria de la posguerra y la inexistencia de una sociedad civil fuerte que había sido el motor del desarrollo del deporte en el primer tercio del siglo XX. No obstante, a partir de mitad de los años 50, los grandes éxitos futbolísticos del Real Madrid, así como escasos pero sonados éxitos deportivos individuales, serán conveniente utilizados por el régimen franquista como escaparate internacional.

El deporte español sufrió, por tanto, una clara "fascistización" mediante la adopción de toda una serie de signos externos como el saludo fascista (Boletín Oficial del Estado, 1937), que debía hacerse antes de cada partido, o el uso por parte de la Selección Nacional de camisas azules, en vez de las rojas, habituales hasta ese momento. Los hombres realizarán ejercicios viriles de marcado carácter militar. Por el contrario, las mujeres practicarán deportes como el baloncesto o el "balonvolea", y actividades como los bailes populares y las gimnasias sueca y rítmica. El atletismo estuvo prohibido para las mujeres desde $1941^{24}$.

\section{La utilización de la información por el fascismo y el franquismo}

Según Chuliá (2001, p. 16) "la política de prensa constituye un área de intervención gubernamental central en todas las dictaduras. A través de la intervención sobre los medios de comunicación, los gobernantes controlan lo que los gobernados conocen". Ese control, unido a la represión política, social y cultural, persigue impedir que se genere una opinión pública que pueda cuestionar el poder y, al mismo tiempo, crear las bases de apoyo social que le garanticen la permanencia en el tiempo. Dentro de la política referente a medios de comunicación, la de prensa escrita siempre ha gozado de un especial tratamiento, seguramente porque "los periódicos son, sin ninguna duda, el principal instrumento de comunicación del que se sirve la clase dirigente para hacer llegar al país los mensajes más importantes, tanto en el plano político como en el cultural" (Tranfaglia, 2005, p. 7). Franco y Mussolini 
eran plenamente conscientes de esta idea y usaron la prensa tanto para dar muestras de una conveniente amistad entre ambos países como para resguardar sus respectivos intereses cuando era necesario.

La influencia italiana en los medios de comunicación españoles se puede constatar en el tratamiento que las autoridades de prensa dieron a la propaganda de aquel país, favorable en todos los sentidos, al menos hasta 1942, año en el que el giro hacia los países Aliados en la guerra fue evidente. El propio Serrano Suñer, de quien Samuel Hoare, embajador británico en España, dijo que controlaba los dos mecanismos de represión más efectivos que existen, la policía y la prensa (1977, p. 58), concedió una posición privilegiada a Italia y Alemania en detrimento de Gran Bretaña o Estados Unidos (Viuda-Serrano, 2010a, p. 1082). Así, en favor de Italia, se ordenaría destacar los "sentimientos cordiales a la Italia fascista" por parte de España ("Consigna de 27 de octubre," 1939), "intensificar la propaganda [...] de la toma de posesión del agregado de prensa italiano" ("Consigna de 3 de octubre," 1940), publicar artículos "cariñosos [...] por el aniversario de la entrada de Italia en la guerra" ("Consigna de 10 de junio," 1941), o intervenir "todos los comentarios de origen distinto al oficioso de Berlín y Roma" sobre los países contendientes (Vicesecretario de Educación Popular, 1941). Por otro lado, se darían instrucciones para la "disminución de noticias de procedencia inglesa" sobre operaciones contra Italia, "para que esta fase de la guerra presente menos interés a ojos de los lectores" ("Consigna de 11 de diciembre," 1940), o se prohibirían "los anuncios [...] de intención política y propaganda inglesa" ("Consigna de 22 de octubre," 1941). Solo a partir de 1942, se intentará un mayor acercamiento a los Aliados, teniendo "un exquisito cuidado" y procurando "que los (titulares) que se refieren a Estados Unidos sean moderados" ("Consigna de 21 de enero," 1942).

No obstante, Italia siempre estuvo por detrás de Alemania en cuanto al éxito propagandístico en España, al menos cuando realmente se hizo necesaria una mayor influencia: tras la guerra civil. Así lo admite el agregado de prensa italiano en Madrid (Nuzzo, 1940, 27 giugno, pp. 2-3), sobre todo porque "Alemania no escatima los medios necesarios para alimentar esta propaganda", "subvenciona periódicos políticos y se puede decir que tiene una prensa propia". Por el contrario, los recursos que usaba Italia "si existen, son invisibles; no tienen la fuerza necesaria para penetrar en la masa del público". Este hecho no era desconocido por el Minculpop que ya tenía informes anteriores de la "superioridad indiscutible en todos los sectores internacionales de la propaganda del Reich" (Koch, 1940, 25 luglio). A pesar de los esfuerzos italianos, Alemania lideraría el sector propagandístico español durante toda la segunda guerra mundial.

En los medios de comunicación italianos existió también un tratamiento favorable hacia la España de Franco, como demuestran diferentes consignas de las autoridades de prensa a los periódicos. Así se ordena llevar a "primera página la rendición de Madrid" ("Disposizione dal Ministero della Cultura Popolare," 1939, 28 marzo); "dar siempre mucho espacio a las noticias de España" ("Disposizione dal Ministero della Cultura Popolare," 1939, 29 marzo); "recordar el acontecimiento de que el 18 de julio de 1936 Franco inició la guerra revolucionaria" ("Disposizione dal 
Ministero della Cultura Popolare," 1942, 18 luglio); "no hacer comentarios contra España, ni siquiera de carácter histórico" ("Disposizione dal Ministero della Cultura Popolare," 1942, 12 ottobre); o "dar relieve al discurso del general Franco pronunciado en el séptimo aniversario de la revolución falangista" ("Disposizione dal Ministero della Cultura Popolare," 1943, 19 luglio). También se intenta salvaguardar la buena imagen de España, no permitiendo la publicación de noticias negativas, como es el caso de la prohibición de publicar "una presunta crisis ministerial en España" ("Disposizione dal Ministero dellal Cultura Popolare," 1941, 24 marzo).

Sin embargo, cuando los intereses españoles chocan con los italianos también se dan órdenes en consecuencia. En plena guerra mundial, se ordena "no ocuparse del convenio sobre el petróleo entre los Estados Unidos y España" ("Disposizione dal Ministero della Cultura Popolare," 1942, 7 aprile); o "no ocuparse del acuerdo comercial germano-español" ("Disposizione dal Ministero della Cultura Popolare," 1942, 18 dicembre). En todo caso, en ocasiones se observa cierto tono de superioridad moral respecto a España. Por ejemplo, durante los últimos meses de la guerra civil se afirmará que "las cosas (para Franco) van bien, con la característica pachorra española" ("Disposizione dal Ministero della Cultura Popolare," 1939, 14 gennaio), dando muestras evidentes de lo que tanto los generales italianos como el propio Mussolini ya habían insinuado en varias ocasiones sobre la escasa capacidad y determinación de Franco y su ejército para terminar la guerra, a pesar de la ayuda de las potencias del Eje (Preston, 2002, pp. 274, 310).

\subsection{Mussolini y la prensa}

Siguiendo a Gori (2000, p. 46), podemos decir que el fascismo, si bien no intervino sobre las manifestaciones artísticas en general y muchas de ellas no estuvieron al servicio del régimen, controló los medios de comunicación de modo riguroso, en especial la prensa, porque su penetración social estaba muy extendida. Si es cierto que durante los primeros años del gobierno de Mussolini la prensa disfrutó de cierta libertad, a partir de 1926, con la supresión de libertades y el comienzo real de la dictadura, el control fue total. Este se hace evidente sobre todo en los años 30, debido a ese intento de mistificación de las virtudes físicas de Mussolini, que se convierte en el centro de la propaganda fascista. Muchos de los intelectuales y periodistas del momento justifican esa utilización de la prensa. Sin embargo, parece que el control de los periódicos deportivos fue más lento:

Mientras que la prensa política ha sido fascistizada, la deportiva aún no se ha puesto al mismo paso. [...] se quiere que la deportiva sea puesta en similar condición, para que, regulada y controlada sea también más fácil su tarea que es de espontánea y desinteresada colaboración con la reordenación deportiva que se ha iniciado ("Stampa Sportiva I," 1929, p. 132).

Como veremos también en el caso español, en Italia se entiende que la prensa en un importante elemento de adoctrinamiento, en especial para la juventud, objetivo prioritario del sistema, a la búsqueda de ese "nuevo italiano": 
¿A quién se dirige y a quién habla principalmente el periódico deportivo? A los jóvenes [...]. En definitiva, son los alumnos para los que el periódico debe representar el maestro. La influencia educativa (es decir didáctica) de los periódicos que llegan a las manos de los jóvenes es universalmente admitida, y no se discute (Rost, 1929, p. 111).

Por tanto, parecía lógico que, dada su importancia y su universalidad, y "precisamente por su difusión entre los jóvenes, no debe limitar su función a la información estrictamente deportiva" (Rost, 1929, p. 111).

En cuanto a la censura de la prensa, en principio, se acepta el libre ejercicio de la crítica, siempre que esta no esté relacionada con "cuestiones estrictamente políticas" o con aquellas "que son fundamentales de la revolución" ("La stampa sportiva e il Regime," 1928, p. 1); expresiones como estas, en vez de aclarar los límites los difuminan más si cabe haciendo de la arbitrariedad una norma.

Mussolini tuvo el control casi absoluto de la prensa durante su mandato a través de la Direzione Genarale di Pubblica Sicurezza del Ministerio del Interior. Ya desde 1923, sacó adelante un decreto ley en el que se concedía al prefecto la facultad de actuar contra el director de un periódico por publicar noticias que perturbaran el orden público o incitaran al odio de clase o a la desobediencia de las leyes ("Regio Decreto-legge $\left.n^{\circ} 3288, " 1923\right)$. La centralización total del control en todas las provincias ("Regio Decreto-legge no 1081," 1924) perseguía no solo lograr la autoridad absoluta del Estado sobre la prensa fascista y sobre los periódicos no fascistas sino, en última instancia, la eliminación total de cualquier foco de oposición en la prensa (Cesari, 1978, p. 16). Por otro lado, las agencias de noticias eran abundantes en Italia, por lo que el objetivo era reducirlas a una sola controlada por el gobierno. Esta agencia única será la agencia Stefani ${ }^{25}$. En diciembre de 1925 se creará la ley más importante de prensa de la Italia fascista ("Legge n 2307," 1925). Esta ley establece la responsabilidad del director de la publicación y su pertenencia a un registro de profesionales del periodismo. Esa responsabilidad conllevaba que un director condenado dos veces por delitos cometidos por medio de la prensa quedaba expulsado de ese registro y, por tanto, la publicación quedaba suspendida en tanto el fiscal general no reconociese otro director.

En octubre de 1926 Mussolini disolvió los partidos políticos y suprimió la escasa prensa de oposición a su régimen que aún sobrevivía. El objetivo principal era el uso de los medios de comunicación para ofrecer una imagen de Italia y del mundo coherente con la política del Régimen en cada momento (Tranfaglia, 2005, p. 11). La prensa, a través fundamentalmente de la prohibición de publicar determinadas noticias y, sobre todo, de la imposición de contenidos, se convertirá en un magnífico instrumento político en manos de Mussolini utilizado para la legitimación del régimen.

A pesar de que en los siguientes años no existió una "censura previa" en el estricto sentido del término, las numerosas consignas ("disposizioni" o "veline") que los organismos de control enviaban casi diariamente a los periódicos condicionaban la libertad de expresión de la prensa. La Oficina de Prensa de Mussolini monopolizó 
la propaganda y aumentó la represión contra los periódicos que no cumplían las órdenes cotidianas.

En 1933 Hitler sube al poder y comienzan a estrecharse las relaciones con Alemania. Se instituye la censura previa para todas las publicaciones. En 1934 se acaba con la Oficina de Prensa y se crea en su lugar el Sottosegretariato di Stato per la Stampa e la Propaganda ("Regio Decreto no 1434," 1934). Esta Subsecretaría se convertirá en el Ministero per la Stampa e la Propaganda ("Regio Decreto n 1009 ," 1935) y, posteriormente, en el mucho más conocido Ministero della Cultura Popolare (Minculpop) en 1937 ("Regio Decreto n 752," 1937).

El uso de constantes consignas dirige la actividad periodística hacia "una ardiente pasión de italianismo y de fascismo, que debe iluminar el periódico en todos sus números"; como en el caso español, se pretende que los periodistas ejerzan una suerte de autocensura de modo que al publicar cualquier cosa, uno siempre se pregunte "si es útil o perjudicial para Italia y para el Régimen" ("Disposizione, 'Rinnovare il tipo di giornale'," 1933). Sin embargo, teóricamente se afirmaba que no se daban a la prensa "órdenes secretas, ni siquiera reservadas, sino solo aclaraciones, orientaciones" (Alfieri, 1937). En ocasiones, hubo quejas de las autoridades sobre la uniformidad de los periódicos, que seguían al pie de la letra las instrucciones del Ministerio de la prensa y la propaganda y ponían los mismos títulos con casi "un único tipo y modelo" en todas las portadas ("Nota del Ministero della Cultura Popolare del 21 ottobre," 1936). Los intentos de solución de este problema, que también se dio en la prensa española, como publicar lo mismo en días distintos por grupos de diarios de mañana, mediodía y tarde ("Disposizione dal Ministero della Cultura Popolare," 1939, 25 settembre), derivaron en otras preocupaciones, a juzgar por un telegrama en el que se denuncian "los graves inconvenientes derivados de la falta de uniformidad de criterios de censura" que les llegan a los periódicos por diferentes medios (Galli, 1943, agosto).

En los años 40, y a pesar de que en 1943 "la censura previa queda abolida" con la autorización de Mussolini ("Appunto per il Duce dal Ministero della Cultura Popolare," 1943, 2 ottobre), la delicada situación internacional y la participación de Italia en la guerra mundial, hizo intensificar, más si cabe, el control a la prensa (Cesari, 1978, p. 79). La mayoría de las consignas persiguen objetivos de propaganda bélica pero siguen cuidándose otros temas de preocupación, sobre todo aquellos que tienen que ver con "la moral y la decencia". Por ejemplo, se prohibe la imagen de "la mujer en pantalones" y "la propaganda de la mujer con pantalones en bicicleta", prefiriéndose el uso más femenino de la falda ("Nota del Ministero della Cultura Popolare del 25 giugno," 1941).

El interesante estudio de las consignas nos aclara la importancia concedida al deporte en cada momento. En 1939, tiene importancia el aspecto económico del deporte. Así, se ordena "evitar absolutamente hablar de traspasos de jugadores de fútbol" ("Disposizione dal Ministero della Cultura Popolare," 1939, 3 agosto). Sin embargo, temas como el deportivo están proscritos de los periódicos en tiempo que guerra, solicitando a los directores que no publiquen "lo que pueda suscitar reacciones en los lectores, sobre todo en referencia a ciertos temas frívolos o de 
diversión: caza, deporte, grandes cifras para artistas, para futbolistas, etc." ("Nota del Ministero della Cultura Popolare del 21 giugno," 1941). El razonamiento es que con seguridad no gustará leer cosas así a los combatientes en el frente. Y es que "el excesivo espacio dado en los periódicos a los eventos deportivos [...] no se corresponde con el clima de guerra" ("Disposizione dal Ministero della Cultura Popolare," 1941, 10 gennaio). Esta orden de comedimiento en el espacio usado para el deporte fue repetidamente incumplida, a juzgar por las sucesivas reiteraciones de la orden el 18 de enero y el 19 de febrero. El espacio dedicado al deporte se acaba reduciendo hasta las dos columnas de modo habitual en los días festivos ("Disposizione dal Ministero della Cultura Popolare," 1941, 8 marzo), si bien en ocasiones se conceden "tres columnas de deporte en lugar de dos" ("Disposizione dal Ministero della Cultura Popolare," 1941, 11 giugno).

\subsection{Franco y la prensa}

Desde el fin de la guerra civil se procedió a la depuración de periodistas ("Orden de 24 de mayo," 1939) para lograr profesionales adictos y dispuestos a colaborar con el nuevo Estado, así como para tomar revancha de aquellos que se habían opuesto al levantamiento de julio de 1936, o no lo habían abrazado con suficiente entusiasmo. La supresión de las libertades contempladas en la constitución republicana conllevaba necesariamente la aparición de una serie de "mecanismos legales de represión y de censura" (Gubern, 1980, p. 19) que garantizaran la consolidación del nuevo orden y que tendrían una labor de doble vertiente: asegurar que nada inconveniente apareciera en los medios de comunicación (acción represiva), pero también orientar a los periodistas sobre qué decir y de qué manera hacerlo (acción preventiva). Los organismos a cargo de la prensa irán variando de denominación y de personas a lo largo de los años. Sin embargo, el férreo control mantendrá su intensidad hasta bien entrados los años 60. Viuda-Serrano (2011, p. 282) define las siguientes como características básicas de esta prensa de posguerra:

La ruptura total con la perniciosa libertad de prensa de la República; la importancia de la prensa como agente adoctrinador y educativo; el control de la verdad única dictada por el Estado; y el apoyo en la prensa para la divulgación de los valores del nuevo régimen y su pervivencia en el tiempo.

Sobre todo en los primeros años de la posguerra, la prensa va a estar en manos de Falange, el partido español de corte fascista fundado por José Antonio Primo de Rivera, bien a través de una prensa propia, que luego se ha denominado "Prensa del Movimiento", bien mediante el control del resto de cabeceras. El marco legal básico es el constituido por la llamada Ley de Prensa de 1938. Inspirada en los principios de exaltación de los años de guerra y nacida como solución "transitoria", marcará las bases del periodismo y la censura de las tres primeras décadas de la dictadura. La prensa, como en el caso italiano, es vista por las autoridades como "órgano decisivo en la formación de la cultura popular y, sobre todo, en la creación de la conciencia colectiva"; y el periodista como "apóstol del pensamiento y de la fe de la Nación" 
("Ley de Prensa de 22 de abril," 1938, p. 6915). Esta ley organiza la estructura censoria (con órganos centrales y provinciales) y establece diversas sanciones para "todo escrito que directa o indirectamente tienda a mermar el prestigio de la Nación o del Régimen, entorpezca la labor de Gobierno [...] o siembre ideas perniciosas entre los intelectualmente débiles (los ciudadanos)" ("Ley de Prensa de 22 de abril," 1938, p. 6917).

Dentro de este marco de actuación, se desarrolló la prensa deportiva durante estos años. Para Shaw (1987, p. 70) "es una opinión difundida la de que el periodista deportivo durante el franquismo gozó de una libertad e independencia que se negaron a la mayoría de sus colegas". Seguramente esta idea, en la que también abunda Duran Froix (2006, p. 65), se pueda desprender, en parte, de las "Normas para los redactores deportivos" publicadas en el primer número del Boletín Oficial de la Delegación Nacional de Deportes (BODND) en abril de 1943, en las que se habla de una cierta "libertad de crítica" limitada solo por el "buen juicio de cada redactor". Sin embargo, parece evidente, a la luz de estudios archivísticos recientes, que la realidad fue otra muy diferente y que la censura actuó con el tema deportivo de manera igual de insistente y arbitraria que con otros temas (Viuda-Serrano, 2010c). El periodismo deportivo fue, por tanto, "organizado, manipulado y controlado" durante todos los años de dictadura (Botines, 1977).

Durante el franquismo existió una acción consciente de ocultación de la precaria realidad por parte del Estado, utilizando para ello los medios de comunicación como herramienta básica de adoctrinamiento popular. Además, se reconoció la especial importancia de la prensa deportiva en el ámbito educativo. Ya en 1941 el órgano encargado del control de la prensa, la Delegación Nacional de Prensa (DNP), reconocía en una consigna política reservada "la gran influencia que sus reseñas y críticas (las de la prensa deportiva) ejercen en la educación popular" (Director General de Prensa, 1941). Y no cabe duda de que la trascendencia del tema deportivo en la prensa se deriva de la importancia social del propio fenómeno del deporte, a la que ya hemos hecho referencia.

El gran problema de la prensa deportiva era, como también lo fue de la general, la uniformidad de contenidos debido a la acción preventiva de la censura. Esta se llevaba a cabo mediante dos herramientas básicas: las notas de inserción obligatoria y las consignas. Las primeras, eran notas de prensa que distintos órganos del Estado tenían interés en publicar. En el caso del deporte español, los organismos que usaron este sistema con mayor asiduidad fueron la Delegación Nacional de Deportes, la Delegación Nacional de la Sección Femenina y la Dirección General de Seguridad ${ }^{26}$. Las consignas, una mezcla "peculiar de consejo y amenaza" (Sinova Garrido, 1989, p. 187), eran claro reflejo de las disposizioni alla Stampa o veline italianas. Estas órdenes de actuación para los periódicos trataron de los temas más diversos, según las necesidades del Estado y, aunque seguramente es imposible dar un número exacto de ellas, el hallazgo en los archivos de multitud de ellas, en muchos casos diarias, y los relatos de periodistas de la época (Delibes, 1985, p. 6), nos permiten afirmar que su uso era cotidiano. 
En cuanto a los temas censurados por las autoridades, en muchas ocasiones resultan ajenos al deporte mismo y se adentran en las posibles conexiones con la política, la economía o el uso del lenguaje. Interesantes ejemplos de consignas o de noticias censuradas se pueden consultar en trabajos ya publicados (Viuda-Serrano, 2011).

\section{Conclusiones}

Hemos repasado los muchos elementos comunes de la utilización del deporte y la prensa en los regímenes fascista y franquista. Benito Mussolini, líder y modelo de la Italia fascista, encarnó los valores más altos del "hombre nuevo" tanto en la política como en el deporte, y la propaganda giró en torno a su figura como catalizador del nuevo ideal.

El modelo franquista no tuvo una identidad propia en ninguno de los dos campos, sino que, dada su indefinición en el terreno ideológico, mimetizó los modos, los mitos y la organización del fascismo. Sin embargo, a pesar de la importante intervención de Falange y de la clara influencia italiana, España no fue un régimen fascista, en gran medida porque la política española se basó en la figura de Franco y en su intento continuado de perpetuarse en el poder; pero también porque la moral católica introdujo un claro rasgo diferenciador de España con respecto a Italia.

Ambos regímenes entendieron la importancia del deporte y la prensa desde muy temprano. Ambos los utilizaron como herramientas de propaganda y legitimación controlando de manera férrea su funcionamiento. $\mathrm{Y}$ en ambos casos, pasaron a un segundo plano, supeditados siempre a los intereses políticos de cada momento. En definitiva, resulta imposible explicar el fascismo y el franquismo sin hacer referencia al deporte y a la prensa, los dos grandes medios de adoctrinamiento estatal. De ello da buena cuenta toda la documentación primaria expuesta en este estudio que arroja nueva luz sobre las relaciones italo-españolas en la época de entreguerras.

\section{Bibliografía}

ACEVEDO, E. (1969). Carta a los celtíberos esposados. Madrid: Magisterio Español. ALFIERI, D. (1937). Rapporto sullo stato della cultura del Regime, Ministero della Cultura Popolare (Vol. busta 113, fasc. 2): Archivio Centrale dello Stato (ACS).

Appunto per il Duce dal Ministero della Cultura Popolare. (1943, 2 ottobre). Ministero della Cultura Popolare, Gabinetto (Vol. busta 142, fasc. Censura preventiva della stampa). Roma: Archivio Centrale dello Stato (ACS).

Appunto per S. E. il Ministro per la Stampa e la Propaganda. (1936, 20 Gennaio).

Ministerio della Cultura Popolare, Gabinetto (Vol. busta 11, fasc. 101). Roma:

Archivio Centrale dello Stato (ACS).

ARENDT, H. (1960). The Origins of Totalitarianism. New York: Meridian Books.

BIANCHI, E. (1934). Sport. Quaderni Giustizia e Libertà (10), 46-50. 
Boletín Oficial del Estado. (1937). Decreto 263 de 24 de abril, estableciendo el saludo nacional. Gobierno del Estado.

BOTINES, A. (1977). La prensa deportiva, liberada. Interviú, 78.

CARR, R., \& FUSI AIZPURÚA, J. P. (1979). España, de la dictadura a la democracia. Barcelona: Planeta.

Carta del Lavoro. (1927, 30 aprile). Gazzetta Ufficiale del Regno d'Italia, 100.

CESARI, M. (1978). La censura nel periodo fascista. Napoli: Liguori Editore.

CHULIÁ, E. (2001). El poder y la palabra. Prensa y poder político en las dictaduras. El régimen de Franco ante la prensa y el periodismo. Madrid: Biblioteca Nueva. Universidad Nacional de Educación a Distancia.

CIRICI, A. (1977). La estética del franquismo. Barcelona: G. Gili.

Consigna de 3 de octubre. (1940). (Vol. (03)49.01 21, caja 75). Madrid: Archivo General de la Administración (AGA).

Consigna de 10 de junio. (1941). (Vol. (03)49.01 21, caja 75). Madrid: Archivo General de la Administración (AGA).

Consigna de 11 de diciembre. (1940). (Vol. (03)49.01 21, caja 75). Madrid: Archivo General de la Administración (AGA).

Consigna de 22 de octubre. (1941). Sección Cultura (Vol. (03)49.01 21, caja 76). Madrid: Archivo General de la Administración (AGA).

Consigna de 27 de octubre. (1939). (Vol. (03)49.01 21, caja 75). Madrid: Archivo General de la Adminstración (AGA).

Consigna interior reservada de 21 de enero. (1942). (Vol. (03)49.01 21, caja 348). Madrid: Archivo General de la Administración (AGA).

DE FELICE, R. (1974). Mussolini il duce. Gli anni del consenso 1929-1936. Torino: Einaudi.

DE FELICE, R. (1976). Fascism. An Informal Introduction to its Theory and Practice. New Brunswick (New Jersey): Transaction Publishers.

DE GRAZIA, V. (1981). The culture of Consent. Mass Organizations of Leisure in Fascist Italy. Cambridge: Cambridge University Press.

Decreto 255, de 19 de abril, disponiendo que Falange Española y Requetés se integren, bajo la jefatura de S. E. el Jefe del Estado, en una sola entidad política, de carácter nacional, que se denominará "Falange Española Tradicionalista de las JONS", quedando disueltas las demás organizaciones y partidos políticos. (1937, 20 de abril). Boletín Oficial del Estado (BOE), 182, 1033-1034.

Decreto 263 de 24 de abril, estableciendo el saludo nacional. (1937, 25 de abril). Boletín Oficial del Estado (BOE), 187, 1106.

Decreto de 9 de marzo. Queda aprobado el Fuero del Trabajador formulado por el Consejo Nacional de Falange Española Tradicionalista y de las J. O. N. S., sobre una ponencia del Gobierno, y que a continuación se publica. (1938, 10 de marzo). Boletín Oficial del Estado (BOE), 505, 6178-6181.

DELIBES, M. (1985). La censura de prensa en los años 40. In M. DELIBES (Ed.), La censura de prensa en los años 40 (y otros ensayos) (pp. 5-30). Valladolid: Ámbito.

Director General de Prensa. (1941). Consigna a todos los directores de periódicos de Madrid, provincias y agencias, de 4 de noviembre, Sección Cultura (Vol. (03)49.01 21, caja 354). Madrid: Archivo General de la Admistración (AGA). 
Disposizione dal Ministero della Cultura Popolare. (1939, 3 agosto). Agenzia Stefani (Vol. busta 71, Fasc. IX, sottofasc. 2). Roma: Archivio Centrale dello Stato (ACS).

Disposizione dal Ministero della Cultura Popolare. (1939, 14 gennaio). Agenzia Stefani (Vol. busta 71, fasc. IX, sottofasc. 2). Roma: Archivio Centrale dello Stato (ACS).

Disposizione dal Ministero della Cultura Popolare. (1939, 25 settembre). Agenzia Stefani (Vol. busta 71, fasc. IX, sottofasc. 2). Roma: Archivio Centrale dello Stato (ACS).

Disposizione dal Ministero della Cultura Popolare. (1939, 28 marzo). Agenzia Stefani (Vol. busta 71, fasc. IX, sottofasc. 2). Roma: Archivio Centrale dello Stato (ACS).

Disposizione dal Ministero della Cultura Popolare. (1939, 29 marzo). Agencia Stefani (Vol. busta 71, fasc. IX, sottofasc. 2). Roma: Archivio Centrale dello Stato (ACS).

Disposizione dal Ministero della Cultura Popolare. (1941, 8 marzo). Agenzia Stefani (Vol. busta 71, fasc. IX, sottofasc. 3). Roma: Archivio Centrale dello Stato (ACS).

Disposizione dal Ministero della Cultura Popolare. (1941, 10 gennaio). Agenzia Stefani (Vol. busta 71, fasc. IX, sottofasc. 3). Roma: Archivio Centrale dello Stato (ACS).

Disposizione dal Ministero della Cultura Popolare. (1941, 11 giugno). Agenzia Stefani (Vol. busta 71, fasc. IX, sottofasc. 3). Roma: Archivio Centrale dello Stato (ACS).

Disposizione dal Ministero della Cultura Popolare. (1941, 27 febbraio). Agenzia Stefani (Vol. busta 71, fasc. IX, sottofasc. 3). Roma: Archivio Centrale dello Stato (ACS).

Disposizione dal Ministero della Cultura Popolare. (1942, 7 aprile). Agenzia Stefani (Vol. busta 72, fasc. IX, sottofasc. 3). Roma: Archivio Centrale dello Stato (ACS).

Disposizione dal Ministero della Cultura Popolare. (1942, 12 ottobre). Agenzia Stefani (Vol. busta 72, fasc. IX, sottofasc. 3). Roma: Archivio Generale dello Stato (ACS).

Disposizione dal Ministero della Cultura Popolare. (1942, 18 dicembre). Agenzia Stefani (Vol. busta 72, fasc. IX, sottofasc. 3). Roma: Archivio Centrale dello Stato (ACS).

Disposizione dal Ministero della Cultura Popolare. (1942, 18 luglio). Agenzia Stefani (Vol. busta 72, fasc. IX, sottofasc. 3). Roma: Archivio Centrale dello Stato (ACS).

Disposizione dal Ministero della Cultura Popolare. (1943, 19 luglio). Agenzia Stefani, Manlio Morgagni (Vol. busta 72, fasc. IX, sottofasc. 3). Roma: Archivio Centrale dello Stato (ACS).

Disposizione dal Ministero dellal Cultura Popolare. (1941, 24 marzo). Agenzia Stefani (Vol. busta 71, fasc. IX, sottofasc. 3). Roma: Archivio Centrale dello Stato (ACS).

Disposizione, 'Rinnovare il tipo di giornale'. (1933). Ministero della Cultura Popolare, Ufficio Stampa (Vol. busta 38): Archivio Centrale dello Stato (ACS).

DURAN FROIX, J. S. (2006). Le football: Le loisir par excellence des espagnols sous le franquisme (1939-debut des années soixante). In S. SALAÜN \& F. ÉTIENVRE (Eds.), Ocio y ocios. Du loisir aux loisirs (Espagne XVIIe-XXe siécles). Paris: Centre de Recherche sur l'Espagne Contemporaine (CREC), Université de la Sorbonne Nouvelle (Paris III).

FERRERO, G. (1991 [1942]). El poder. Los genios invisibles de la ciudad. Madrid: Tecnos.

FERRETTI, L. (1928a, Settembre). Il C.O.N.I. e la sua opera. Lo Sport Fascista. Rassegna Mensile Illustrata, 4, 2-5.

FERRETTI, L. (1928b, Giugno). Programma. Lo Sport Fascista. Rivista Mensile Illustrata, 1, 3-4. 
FERRETTI, L. (1933, Gennaio). Mussolini, primo sportivo d'Italia. Lo Sport Fascista. Rassegna Mensile Ilustrata, 1, 1-3.

FRANCO BAHAMONDE, F. (1975a). Pensamiento político de Franco (Vol. I). Madrid: Ediciones del Movimiento.

FRANCO BAHAMONDE, F. (1975b). Pensamiento político de Franco (Vol. II). Madrid: Ediciones del Movimiento.

FRIEDRICH, C., \& BRZEZINSKI, Z. (1965). Totalitarian Dictatorship and Autocracy. New York: Frederick A. Praeger.

GALLI, C. (1943, agosto). Telegramma del Ministro della Cultura Popolare alla Presidenza del Consiglio dei Ministri, Ministero della Cultura Popolare, Gabinetto (Vol. busta 142, fasc. Censura preventiva della stampa). Roma: Archivio Centrale dello Stato (ACS).

GONZÁlEZ AJA, T. (2000). Fascists and Christians! In the Spanish Martial Tradition of the Soldier-Monk. In J. A. MANGAN (Ed.), Superman Supreme. Fascist Body as Political Icon - Global Fascism (pp. 119-144). London-Portland: Frank Cass.

GONZÁLEZ AJA, T. (2010). ¿Mens sana in corpore sano? In J. SAMPEDRO MOLINUEVO, T. GONZÁLEZ AJA \& N. GARCÍA-ARJONA (Eds.), El atleta olímpico: ¿transmisor de valores? Una aproximación histórico-científica (pp. 187-214). Madrid: Atos Origin.

GORI, G. (2000). Model of Masculinity: Mussolini, the 'New Italian' of the Fascist Era. In J. A. MANGAN (Ed.), Superman Supreme. Fascist Body as Political Icon - Global Fascism (pp. 27-61). London-Portland: Frank Cass.

GREGOR, A. J. (1974). Interpretations of Fascism. Morristown: General Learning Press.

GROUSSARD, S. (1958, 12 de junio). Chez ceux qui mènent le monde: Franco. Le Figaro, pp. 4-5.

GUBERN, R. (1980). La censura. Función política y ordenamiento jurídico bajo el franquismo (1936-1975). Barcelona: Península.

GUTTMANN, A. (2004). Sports. The First Five Millennia. Amherst-Boston: University of Massachusetts Press.

HOARE, S. (1977). Embajador ante Franco en misión especial. Madrid: Sedmay.

IMPIGLIA, M. (2009). Mussolini sportivo. In M. CANELLA \& S. GIUNTINI (Eds.), Sport e fascismo (pp. 19-45). Milano: Franco Angeli.

KOCH, A. (1940, 25 luglio). Appunto della Direzione Generale Stampa Estera per il Ministro della Cultura Popolare, Ministero della Cultura Popolare (Vol. busta 207). Roma: Archivio Generale dello Stato (ACS).

KRÜGER, A. (1999). Strength through joy. The culture of consent under fascism, Nazism and Francoism. In J. RIORDAN \& A. KRÜGER (Eds.), The International Politics of Sport in the Twentieth Century (pp. 67-89). London-New York: E \& F Spon.

La stampa sportiva e il Regime. (1928, Ottobre). Lo Sport Fascista. Rassegna Mensile Illustrata, 5, 1-2.

Legge $n^{\circ} 300$ del 4 aprile, istituzione dell'Ente Stampa. (1940, 3 maggio). Gazzetta Ufficiale del Regno d'Italia, 104.

Legge $\mathrm{n}^{\circ}$ 2307, Disposizioni sulla stampa periodica. (1925, 31 dicembre). Gazzeta Ufficiale del Regno d'Italia, 3. 
LEWIS, P. H. (2002). Latin fascist elites: the Mussolini, Franco, and Salazar regimes. Westport: Greenwood Publishing Group.

Ley de Prensa de 22 de abril. (1938, 23 de abril). Boletín Oficial del Estado, 549, 69156917.

MANRIQUE ARRIBAS, J. C. (2011). Juventud, deporte y falangismo. El Frente de Juventudes, la Sección Femenina y los deportes del "Movimiento". In X. PUJADAS (Ed.), Atletas y ciudadanos. Historia social del deporte en España, 1870-2010 (pp. 233-272). Madrid: Alianza.

MARTIN, S. (2004). Football and Fascism. The National Game under Mussolini. New York: Berg.

MURRO, R. (1931). Una realtà italina che sarà domani una realtà europea. Gioventù Fascista. Decadale del P. N. F., 12, 6.

MUSSOLINI, B. (1928, 19 settembre). Lo sport e la parola del Duce. La Gazzetta dello Sport.

MUSSOLINI, B. (1931a). Discorso di Torino, 23 Ottobre 1930. Gioventù Fascista. Decadale del P. N. F., 7, 3.

MUSSOLINI, B. (1931b, 10 Gennaio). Il Duce ai giovani. Gioventù Fascista. Decadale del P. N. F., 1, 3.

Normas para los redactores deportivos. (1943). Boletín Oficial de la Delegación Nacional de Deportes, $1,8$.

Nota del Ministero della Cultura Popolare del 21 giugno. (1941). Ministero della Cultura Popolare (Vol. busta 76): Archivio Centrale dello Stato (ACS).

Nota del Ministero della Cultura Popolare del 21 ottobre. (1936). Segreteria particolare del Duce, carteggio ordinario (1922-43) (Vol. $1^{\circ}$ ): Archivio Centrale dello Stato (ACS).

Nota del Ministero della Cultura Popolare del 25 giugno. (1941). Ministero della Cultura Popolare (Vol. busta 76): Archivio Centrale dello Stato (ACS).

NUZZO, G. (1940, 27 giugno). Propaganda nella Spagna, Ministero della Cultura Popolare (Vol. busta 207). Roma: Archivio Centrale dello Stato (ACS).

Orden de 24 de mayo. (1939, 25 de mayo). Boletín Oficial del Estado, 145, 2822-2823.

ORTEGA Y GASSET, J. (2007). Sobre el fascismo. Sine ira et studio. In J. ORTEGA Y GASSET (Ed.), El espectador. Sobre el fascismo. Democracia morbosa. Hegel y América. La interpretación bélica de la historia. Socialización del hombre, etc. (pp. 105-118). Madrid: Edaf.

PARBONI, A. (1928, Novembre). Lo sport nella concezione fascista. Lo Sport Fascista. Rassegna Mensile Illustrata, 6, 1-5.

PASSMORE, K. (2002). Fascism. A Very Short Introduction. New York: Oxford University Press.

PAYNE, S. (2009 [1982]). El fascismo. Madrid: Alianza.

PRESTON, P. (1986). Las derechas españolas en el siglo XX: autoritarismo, fascismo y golpismo. Madrid: Sistema.

PRESTON, P. (2002). Franco, “Caudillo de España”. Barcelona: Grijalbo.

Rapporto ai giornalisti del 14 settembre. (1940). Ministero della Cultura Popolare (Vol. busta 75): Archivio Centrale dello Stato (ACS).

Regio Decreto $\mathrm{n}^{\mathrm{o}} 752$ del 27 maggio, Modificazione della denominazione del Ministero per la stampa e la propaganda. (1937, 1 giugno). Gazzetta Ufficiale del Regno d'Italia, 125. 
Regio Decreto no 1009 del 24 giugno, che istituisce il ministero per la stampa e la propaganda. (1935, 26 giugno). Gazzetta Ufficiale del Regno d'Italia, 148.

Regio Decreto $\mathrm{n}^{\circ} 1434$ del 6 settembre, che istituisce, alla diretta dipendenza del Capo del Governo, il sottosegretariato di Stato per la stampa e la propaganda. $(1934,11$ settembre). Gazzetta Ufficiale del Regno d'Italia, 213.

Regio Decreto-legge $n^{\circ}$ 1081, Norme di attuazione del R. Decreto-legge 15 luglio 1923 $\mathrm{n}^{\circ}$ 3288. (1924). Gazzetta Ufficiale del Regno d'Italia, 162.

Regio Decreto-legge $n^{\circ} 3288$, Norme sulla gerenza e vigilanza dei giornali e delle pubblicazioni periodiche. (1923, 15 luglio). Gazzetta Ufficiale del Regno d'Italia, 159.

ROST, P. (1929, Luglio). Stampa Sportiva IV. Lo Sport Fascista. Rassegna Mensile Illustrata, 7, 111.

ROUSSEAU, J. J. (2007). El contrato social o principios del derecho político. Madrid: Tecnos.

SANTACANA I TORRES, C. (2011). Espejo de un régimen. Transformación de las estructuras deportivas y su uso político y propagandístico, 1939-1961. In X. PUJADAS (Ed.), Atletas y ciudadanos. Historia social del deporte en España, 18702010 (pp. 205-232). Madrid: Alianza.

SAÑA, H. (1981). El franquismo sin mitos. Conversaciones con Serrano Suñer. Barcelona: Grijalbo.

SAZ CAMPOS, I. (1992). El fracaso del éxito: Italia en la guerra de España. Espacio, Tiempo y Forma, Serie V, Historia Contemporánea, V, 105-128.

SERRANO SUÑER, R. (1977). Entre el silencio y la propaganda, la Historia como fue. Memorias. Barcelona: Planeta.

SHAW, D. (1987). Fútbol y franquismo. Madrid: Alianza.

SINOVA GARRIDO, J. (1989). La censura de Prensa durante el franquismo (19361951). Madrid: Espasa-Calpe.

SOUTHWORTH, H. R. (2008 [1964]). El mito de la cruzada de Franco. Barcelona: Random House Mondadori [Debolsillo].

Stampa sportiva i. (1929, Giugno). Lo Sport Fascista. Rassegna Mensile Illustrata, 6, 132.

TEJA, A. (2002). Deporte y relaciones internacionales durante el fascismo en Italia. In T. GONZÁLEZ AJA (Ed.), Sport y autoritarismos. La utilización del deporte por el comunismo y el fascismo (pp. 241-280). Madrid: Alianza.

THOMAS, H. (1976). La guerra civil española (Vol. 2). Barcelona: Grijalbo.

TRANFAGLIA, N. (2005). La stampa del Regime, 1932-1943. Le veline del Minculpop per orientare l'informazione. Milano: Saggi Bompiani.

TURNER Jr., H. A. (1975). Reappraisals of Fascism. New York: New Viewpoints.

TUSELL, J., \& GARCÍA QUEIPO DE LLANO, G. (2006). Franco y Mussolini. La política española durante la segunda guerra mundial. Barcelona: Ediciones Península.

VARALE, V. (1930, Marzo). Per la sanità della razza. Lo Sport Fascista. Ressegna Mensile Illustrata, 3, 1-2.

VARALE, V. (1933, Maggio). Mentalitá fascista degli sportivi. Lo Sport Fascista. Rassegna Mensile Illustrata, 5, 1-4.

VESCOVI, R. (2003). Children into Soldiers: Sport and Fascist Italy. In J. A. MANGAN (Ed.), Militarism, Sport, Europe. War without Weapons (pp. 166-186). London: Frank Cass. 
VICESECRETARIO DE EDUCACIÓN POPULAR. (1941). Consigna de la Vicesecretaría de Educación Popular no 18, de 19 de junio (Vol. (03)49.01 21, caja 354). Madrid: Archivo General de la Adminstración (AGA).

VIUDA-SERRANO, A. (2010a). A Diplomatic Mission: Spain and the 1948 London Olympics. The International Journal of the Histroy of Sport, 27(6), 1080-1103.

VIUDA-SERRANO, A. (2010b). El atleta de la Posguerra Civil Española. La transmisión de los valores franquistas a través de la censura. In J. SAMPEDRO MOLINUEVO, T. GONZÁLEZ AJA \& N. GARCÍA-ARJONA (Eds.), El atleta olímpico: ¿transmisor de valores? Una aproximación histórico-científica (pp. 157-176). Madrid: Atos Origin.

VIUDA-SERRANO, A. (2010c). Forbidden Words. The Censorship of Sport in the Spanish Press after the Civil War (1942-1943). European Studies in Sports History, 3, 67-78.

VIUDA-SERRANO, A. (2011). Deporte, censura y represión bajo el franquismo, 19391961. In X. PUJADAS (Ed.), Atletas y ciudadanos. Historia social del deporte en España (1870-2010) (pp. 273-321). Madrid: Alianza.

WOOLF, S. J. (1965). Introduction. In S. J. WOOLF (Ed.), European Fascism. New York: Vintage Books.

\section{Notas}

1 Véanse a este respecto Gentile, E., Di Febo, G., Sueiro Seoane, S., \& Tusell, J. (2004). Fascismo y franquismo cara a cara: una perspectiva histórica. Madrid: Biblioteca Nueva; Saz Campos, I. (2004). Fascismo y franquismo. Barcelona: Publicaciones de la Universitat de València.

2 Véanse Heiberg, M. (2001). Mussolini, Franco and the spanish Civil War: An Afterthought. Totalitarian Movements and Political Religions, 2(3), 55-68; Carotenuto, G. (2005). Franco e Mussolini. La guerra mondiale vista dal Mediterraneo: $i$ diversi destini dei due dittatori. Milano: Sperling \& Kupfer; Tusell, J., \& García Queipo de Llano, G. (2006). Franco y Mussolini. La política española durante la segunda guerra mundial. Barcelona: Ediciones Península; Canosa, R. (2008). Mussolini e Franco. Amici, alleati, rivali: vite parallele di due dittatori. Milano: Mondadori.

3 Véanse Tusell, J., \& Saz Campos, I. (1982). Mussolini y Primo de Rivera: Las relaciones políticas y económicas de dos dictaduras mediterráneas. Boletín de la Real Academia de la Historia (BRAH), CLXXIX(III), 413-483; Palomares Lerma, G. (1989). Mussolini y Primo de Rivera. Política exterior de dos dictadores. Madrid: EUDEMA; Saz Campos, I. (1992). El fracaso del éxito: Italia en la guerra de España. Espacio, Tiempo y Forma, Serie V, Historia Contemporánea, V, 105-128.

4 Lo mismo ocurriría en 1940, cuando Mussolini entró en la segunda guerra mundial para obtener beneficios a corto plazo confiando en la rápida victoria alemana; y también se equivocó. 
5 Véanse, a propósito de este tema, las interesantes aportaciones de Saz Campos, I. (1992). El fracaso del éxito: Italia en la guerra de España. Espacio, Tiempo y Forma, Serie V, Historia Contemporánea, V, 105-128.

6 Entre los más interesantes se encuentran Meynaud, J. (1972). El deporte y la política. Análisis social de unas relaciones ocultas. Barcelona: Editorial Hispano Europea; Cazorla Prieto, L. M. (1979). Deporte y Estado. Madrid: Labor; Riordan, J., \& Krüger, A. (1999). The International Politics of Sport in the Twentieth Century. London-New York: E \& FN Spon.

7 Entre los específicamente dedicados al deporte fascista destacamos: Fabrizio, F. (1976). Sport e fascismo. La politica sportiva del regime, 1928-1936. RiminiFlorence: Guaraldi; Bianda, R., Leone, G., Rossi, G., \& Urso, A. (1983). Atletici in camicia nera: lo sport nell'Italia di Mussolini. Roma: Giovanni Volpe; Mangan, J. A. (1999). Shaping the Superman. Fascist Body as Political Icon - Aryan Fascism. London-Portland: Frank Cass; Mangan, J. A. (2000). Superman Supreme. Fascist Body as Political Icon - Global Fascism. London-Portland: Frank Cass; Bacci, A. (2002). Lo sport nella propaganda fascista. Torino: Bradipolibri; Gori, G. (2004). Italian Fascism and the Female Body. Sport, Submissive Women and Strong Mothers. London-New York: Routledge; Martin, S. (2004). Football and Fascism. The National Game under Mussolini. New York: Berg; Canella, M., \& Giuntini, S. (2009). Sport e fascismo. Milano: Franco Angeli. En cuanto al deporte franquista: Shaw, D. (1987). Fútbol y franquismo. Madrid: Alianza; González Aja, T. (2002). Sport y autoritarismos. La utilización del deporte por el comunismo y el fascismo. Madrid: Alianza.

8 Véase sobre las diferencias entre Franco y Mussolini como figuras deportivas González Aja, T., \& Teja, A. (1997). Mussolini and Franco sportmen: two contrasting fascist conceptions of sports. In A. Krüger \& A. Teja (Eds.), La comune eredità dello sport in Europa. Atti del 1. Seminario Europeo di Storia dello Sport. Rome: Scuola dello Sport-CONI.

9 Véase sobre la imagen de ese nuevo hombre forjado por el fascismo Mosse, G. L. (1996). The Image of Man. The Creation of Modern Masculinity. New York: Oxford University Press.

10 Veamos como ejemplo que de entre todos los números de Gioventù Fascista publicados en el año 1931 (28), la imagen de Benito Mussolini aparece en el 68\% de las portadas, si bien en un $14 \%$ de esas imágenes no se le distingue por tratarse de fotografías panorámicas de discursos y aclamaciones populares. En un $16 \%$ de esas portadas el Duce aparece en actividades deportivas como jinete, aviador y marinero. [Datos recopilados por los autores].

11 Son ejemplos claros las aparecidas en Lo Sport Fascista, publicación mensual sobre el deporte italiano, como la dedicada por él mismo, y fechada el 4 de mayo de 1928, en la que aparece vestido para la práctica de la esgrima, empuñando la espada con la mano derecha y sujetando el casco con la izquierda (número 1 de junio de 1928); u otra montado sobre "Zibudoff", caballo italiano según aclara el pie de foto, vestido con chaqueta, corbata y bombín (número 10 de octubre de 1929). Pero sobre todo, la 
portada dedicada en exclusiva a Mussolini: una fotocomposición con imágenes en coche, en moto, en avioneta, a caballo y con la espada, y el texto "El Duce, primer deportista de Italia en el cielo, en el mar y en la tierra" (número 1 de enero de 1933).

12 Legge no 2247 del 3 aprile 1926, Istituzione dell'Opera nazionale "Balilla" per l'assistenza e l'educazione física e morale della gioventù. (1927, 11 gennaio). Gazzetta Ufficiale del Regno d'Italia, 7.

13 Regio Decreto-legge $n^{\circ} 1839$ del 27 ottobre, Istituzione della Gioventù italiana del Littorio. (1937, 12 novembre). Gazzetta Ufficiale del Regno d'Italia, 262.

14 Regio Decreto-legge $n^{\circ} 582$ del 1 maggio, Istituzione dell'Opera nazionale del dopolavoro. (1925, 14 maggio). Gazzetta Ufficiale del Regno d'Italia, 112.

15 Nacidos en 1919. Véase La Rovere, L. (2003). Storia dei Guf. Organizzazione, politica e miti della gioventù universitaria fascista, 1919-1943. Torino: Bollati Boringhieri.

16 Fundado en junio de 1914.

17 Los celebrados en Viena fueron organizados por la Union Internationale des Étudiants (UIE). Sin embargo, otros Juegos Universitarios Internacionales se celebraron en Monaco el mismo año y fueron organizados por la Confederation Internationale des Étudiants (CIE).

18 Ley de 6 de diciembre de 1940 instituyendo el Frente de Juventudes. (1940, 7 diciembre). Boletín Oficial del Estado (BOE), 342.

19 Decreto número 414 de 21 de noviembre, por el que se aprueban los Estatutos del Sindicato Español Universitario de FET y de las JONS. (1937, 23 noviembre). Boletín Oficial del Estado (BOE), 399.

20 Decreto de 28 de diciembre, sobre funciones de la Sección Femenina de FET y de las JONS. (1939, 29 diciembre). Boletín Oficial del Estado (BOE), 363.

21 Ley de Bases de la Organización Sindical de 6 de diciembre. (1940, 7 diciembre). Boletín Oficial del Estado (BOE), 342.

22 Decreto de 22 de febrero, por el que se establece la Delegación Nacional de Deportes de FET y de las JONS. (1941, 5 marzo). Boletín Oficial del Estado (BOE), 64.

23 Decreto de 27 de agosto, sobre constitución y reconocimiento del Comité Olímpico Español. (1938, 29 agosto). Boletín Oficial del Estado (BOE), 60.

24 Con seguridad tuvo mucho que ver en ello el caso de María Torremadé, deportista que batió un gran número de récords de atletismo pero que resultó ser Jordi, tras rectificar su sexo en el Registro Civil.

25 Véase en el Archivio Centrale dello Stato de Roma, la abundantísima información del fondo documental denominado "Agenzia Stefani”.

26 Véase a este respecto la documentación del Archivo General de la Administración (AGA), por ejemplo para 1943: Sección Cultura (03)49.01 21, cajas 673 y 677. 


\section{Los autores}

Alejandro Viuda-Serrano es profesor de Historia del Deporte en la Universidad Camilo José Cela y licenciado en Ciencias del Deporte (UPM) y en Ciencias de la Información (UCM). Sus líneas de investigación se centran en las relaciones entre el deporte y la prensa, así como en la censura durante elfranquismo.

Teresa González Aja es catedrática de la Universidad Politécnica de Madrid, profesora de Historia del Deporte en la UPM y doctora en Historia (UCM). Su trayectoria ha estado marcada por el estudio de la imagen y el deporte, además de las relaciones internacionales del deporte español y su evolución histórica durante el siglo $\mathrm{XX}$. 